\title{
Challenges and Opportunities in Conducting Translational and Clinical Research in Academic Institutions and Universities
}

\author{
Sohail Rao, MD, MA, DPhil ${ }^{1,2}$ \\ ${ }^{1}$ Executive Vice President, DHR Health, 5501 S. McColl Road, Edinburg, Texas 78539 and President \\ \& Chief Executive Officer, DHR Health Institute for Research \& Development, 5323 S. McColl Road, \\ Edinburg, Texas 78539. \\ ORCID: https://orcid.org/0000-0001-5027-9992 \\ ${ }^{2}$ Correspondence should be addressed to: Sohail Rao, MD, MA, DPhil., DHR Health Institute for \\ Research \& Development, 5323 S. McColl Road, Edinburg, Texas 78539. Tel: (956) 362-2387. E-mail: \\ s.rao@dhr-rgv.com
}

Received 03/01/2022

Accepted for publication 03/01/2022

Published 03/01/2022

Keywords: Clinical Research; Translational Research; Independent Research Centers

\begin{abstract}
The global clinical trials market size was estimated at USD 44.3 billion in 2020 and is expected to expand at a compound annual growth rate of $5.7 \%$ from 2021 to 2028 . However, the market growth was hindered in 2020 due to the COVID-19 pandemic. Nevertheless, the future seems promising for the market owing to factors such as globalization of clinical trials, rapid technological evolution, and augmenting demand for clinical research organizations to conduct research activities. The increasing prevalence of chronic disease and the growing demand for clinical trials in developing countries are also fueling this market's growth. The market is also driven by a rising number of biologics, the need for personalized medicines and orphan drugs, and demand for advanced technologies.
\end{abstract}

Cooperation among a diverse group of stakeholdersincluding research sponsors (industry, academia, government, nonprofit organizations, clinical research organizations, and patient advocates), clinical investigators, patients, payers, physicians, and regulators-is necessary in conducting a clinical trial today. Each stakeholder offers a different set of tools to support the essential components of a clinical trial. These resources form the infrastructure that currently supports clinical research in the United States. Time, money, personnel, materials (e.g., medical supplies), support systems (informatics as well as manpower), and a clear plan for completing the necessary steps in a trial are all part of the clinical research infrastructure. Most clinical trials are conducted in a "one-off" manner in which the necessary components of a trial (usually a single coordinating center and multiple research sites) are brought together for a discrete period of time and disbanded once the trial is completed.

It is interesting to note that fewer than half of all the medical treatments delivered today are supported by evidence and yet the United States lacks a clear prioritization of the gaps in medical evidence and allocation of clinical research resources to fill these evidence gaps efficiently and effectively (1). The federal government, industry, academic institutions, patient advocacy organizations, voluntary health organizations, and payers each have incentives to develop research questions that suit their unique interests. The value of a particular research effort is judged by stakeholders according to their own cost-benefit calculation. Reflecting the diversity of stakeholder value judgments, and in the absence of a broad national agenda, clinical trials are conducted in a "one-off," narrowly focused fashion.

Because clinical trials are necessary to obtain regulatory approval in the United States, they are a high priority to companies. Therefore, prioritization of clinical research questions by companies seeking regulatory approval is distinctly different from the priorities of society in general, which may prioritize the comparison of two commonly used therapies. This divergence between the priorities of society 
and industry is notable as the nation discusses how to address the current gaps in clinical research and medical decision making.

Significant time, energy, and money are spent on bringing the disparate resources for each trial together. It is therefore reasonable to argue that efficiencies could be gained by streamlining the clinical trials infrastructure so that those investigating new research questions could quickly draw on resources already in place instead of reinventing the wheel for each trial. The process for obtaining US Food and Drug Administration approval for a drug and/or a biological agent is extremely protracted and cumbrous. On an average, it takes 10-17 years for a drug to be approved for use in humans costing in most instances millions of dollars to the biopharmaceutical industry (Figure 1). Therefore, it is imperative that entities involved in clinical research focus on managing the time to recruitment of the first patient in each trial an outcome that can only be accomplished by having a streamlined process (Table 1). They must also ensure that the data is of the highest quality and available to the sponsors in a timely manner and that the research subjects screened and/or accrued in each clinical trial must meet the inclusion and exclusion criteria outlined in the protocol.

Figure 1: Time to Completion of Various Phases of Clinical Trials and the Number of Biological Molecules Tested to Yield one (1) FDA-approved Drug

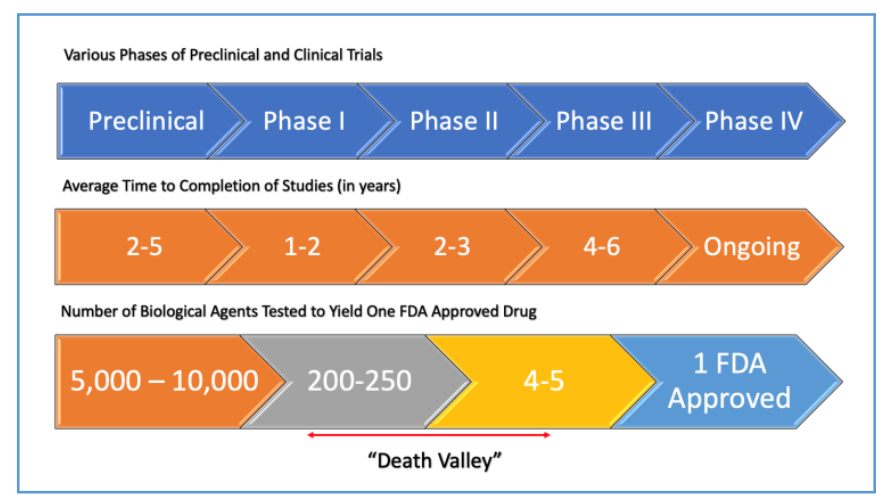

In the past, clinical research was performed primarily at major academic centers and universities. However, today most clinical research is performed in independent research centers and private clinics throughout the country. Many of the changes were brought on by rising costs in health care and the growing bureaucracies in academic institutions that have made initiating clinical research an onerous task in these entities.

The practice of evidence-based medicine is at the core of providing quality and innovative clinical care and to accomplish this objective, it is quintessential for any organization involved in patient care to conduct translational and clinical research. Therefore, if academic institutions and universities who are involved in clinical care, are serious about regaining their share of translational and clinical research, they must undergo a transformational change and adopt a more streamlined process for initiating trials in their facilities and work towards eliminating the unnecessary burden of administrative bureaucracy that has resulted in this outcome.

Table 1: Critical Components of a Streamlined Review, Approval, and Implementation Process for a Successful Clinical Research Trial

\begin{tabular}{|c|c|}
\hline REGULATORY & $\begin{array}{ll}\text { - } & \text { Succinct Policies \& } \\
\text { Guidelines } \\
\text { - } & \text { Patient-centered Institution } \\
& \text { Review Board (IRB) }\end{array}$ \\
\hline OPERATIONS & $\begin{array}{ll}\text { - } & \text { Master Affiliation } \\
\text { - } & \text { Agreements with Sponsors } \\
\text { - } & \text { Confidentiality/Non- } \\
& \text { disclosure Agreements }\end{array}$ \\
\hline TECHNOLOGY & $\begin{array}{ll}\text { - } & \text { Feasibility Studies } \\
\text { - } & \text { Electronic Data Capture } \\
& \text { Application } \\
\text { - } & \text { User-friendly Electronic } \\
& \text { Medical Record } \\
\text { - } & \text { Investigator-friendly } \\
& \text { Electronic IRB Submission } \\
& \text { Software }\end{array}$ \\
\hline PERSONNEL & $\begin{array}{ll}\text { - } & \text { Physician Investigator } \\
\text { - } & \text { Advanced Practice Nurse (if } \\
\text { required) } \\
\text { - } \\
\text { Experience Clinical Research } \\
\text { Coordinator } \\
\text { - } \\
\text { Support Staff (Medical } \\
\text { assistants, Phlebotomist, Data } \\
\text { Managers, etc) } \\
\text { Research Information } \\
\text { Technologists }\end{array}$ \\
\hline INFRASTRUCTURE & $\begin{array}{l}\text { Adequate space, Equipment, } \\
\text { and Supplies }\end{array}$ \\
\hline
\end{tabular}

It is our recommendation that for academic institutions and universities to be successful in conducting translational and clinical research, they must seriously consider establishing an independent nonprofit research institute that is tasked with the responsibility of managing the entire process and have all the critical components under one roof that are outlined in 
Table 1. This would be in the best interest of the academic institutions and the universities as it would isolate the inherent risk and liability associated with the conduct of clinical trials. Lastly, the person assigned to lead this process must be a visionary who is a seasoned clinical investigator and research administrator with documented experience and expertise in establishing and managing such entities.

\section{Diclosures}

SR declares no conflicts of interest.

\section{Funding}

The project is funded by a Seed Grant from the DHR Health Institute for Research \& Development

\section{References}

1. Institute of Medicine (US) Roundtable on EvidenceBased Medicine. The Healthcare Imperative: Lowering Costs and Improving Outcomes: Workshop Series Summary. Yong PL, Saunders RS, Olsen L, editors. Washington (DC): National Academies Press (US); 2010. PMID: 21595114. 